\title{
Central nervous system manifestations of multiple myeloma: risk and prognostic considerations
}

\author{
Cheri D Leary, PA-C; Amy M Bozeman, PA-C; Wenli Gao, MD; Diana Veillon, MD; \\ Nebu V Koshy, MD; James Cotelingam, MD; and Reinhold Munker, MD
}

Blood and Marrow Transplant, University Health, Shreveport, Louisiana

$\mathrm{M}$ ultiple myeloma accounts for about $1 \%$ of all cancers and for $10 \%$ of hematologic malignancies in the United States. The incidence rate ranges from $4-5$ per 100,000 population. ${ }^{1}$ It is characterized by the neoplastic proliferation of a clone of plasma cells that produces monoclonal immunoglobulin and presents as focal or disseminated plasma cell dyscrasia. ${ }^{1,2}$ This clone of plasma cells usually multiplies in the bone marrow and often results in end-organ damage including anemia, osteolytic lesions, hypercalcemia, and abnormal kidney function. The involvement of the central nervous system (CNS) in multiple myeloma is uncommon, but can present at initial diagnosis ${ }^{3}$ or later in the course of the disease. More common causes of neurological symptoms in multiple myeloma include hypercalcemia, uremia, spinal cord or nerve root compression, and peripheral neuropathies. ${ }^{4}$ Risk factors linked to the development of CNS disease include unfavorable cytogenetics, heavy tumor burden, plasmablastic morphology, and extramedullary disease. ${ }^{5,6}$ In this report, we describe 2 patients who developed CNS involvement after autologous stem cell transplant (ASCT) in the context of extramedullary disease.

\section{Case presentations and summaries Case 1}

A 68-year-old African American woman diagnosed with stage III IgA kappa multiple myeloma, according to the International Staging System, presented with anemia (hemoglobin, $8.3 \mathrm{~g} / \mathrm{dL}$; normal range, $11.3-15.4 \mathrm{~g} / \mathrm{dL}$ ) and an elevated beta- 2 microglobulin of $5.5 \mathrm{mg} / \mathrm{L}$ (normal range, $0.6-2.4 \mathrm{mg} / \mathrm{L}$ ); but she had no other evidence of end-organ disease. A bone marrow core biopsy revealed 45\% CD138- positive plasma cells by immunohistochemistry and kappa light chain restriction on in situ hybridization staining. Conventional cytogenetic studies were normal, and molecular cytogenetic studies by fluorescence in situ hybridization (FISH) for myelomaassociated abnormalities were not performed. The patient received induction chemotherapy with the Cy-Bor-D regimen (cyclophosphamide, bortezomib, dexamethasone) and completed 3 cycles, which resulted in stable disease. The dosage information for this regimen was not available to us as the patient was a referral from another facility. However, 6 months after diagnosis a new pleural-based lesion was noted on skeletal survey. A subsequent fludeoxyglucose positron emission tomography (FDGPET) scan showed a large destructive rib mass in the lower right chest cavity and 2 areas of lymph node involvement in the supraclavicular region and midesophageal para-aortic region, consistent with extramedullary disease. Biopsy of the pleural lesion showed plasma cell myeloma. The patient was switched to the DT-PACE regimen (dexamethasone $40 \mathrm{mg}$ orally daily for 4 days; thalidomide 400 $\mathrm{mg}$ PO at night; 4-day continuous infusion of cisplatin $10 \mathrm{mg} / \mathrm{m}^{2}$ a day, doxorubicin $10 \mathrm{mg} / \mathrm{m}^{2}$ a day, cyclophosphamide $400 \mathrm{mg} / \mathrm{m}^{2}$ a day, and etoposide $40 \mathrm{mg} / \mathrm{m}^{2}$ ) every 21 days, and she completed 2 cycles with partial remission. The results of a repeat PET scan showed a dramatic response to the chemotherapy with some residual osseous lesions. Moderate improvement was noted in the involved paraesophageal node. The patient underwent an ASCT 10 months after her initial diagnosis with complete metabolic response on PET scan and stable disease noted on restaging laboratory studies.

The patient presented 6 months after the ASCT

Accepted for publication November 11, 2015. Correspondence: Cheri Leary, PA-C; Cheri.Leary@uhsystem.com. Disclosures: The authors report no disclosures or conflicts of interest. JCSO 2016;14(10):427-430. @2016 Frontline Medical Communications. doi: 10.12788/jicso.0224. 


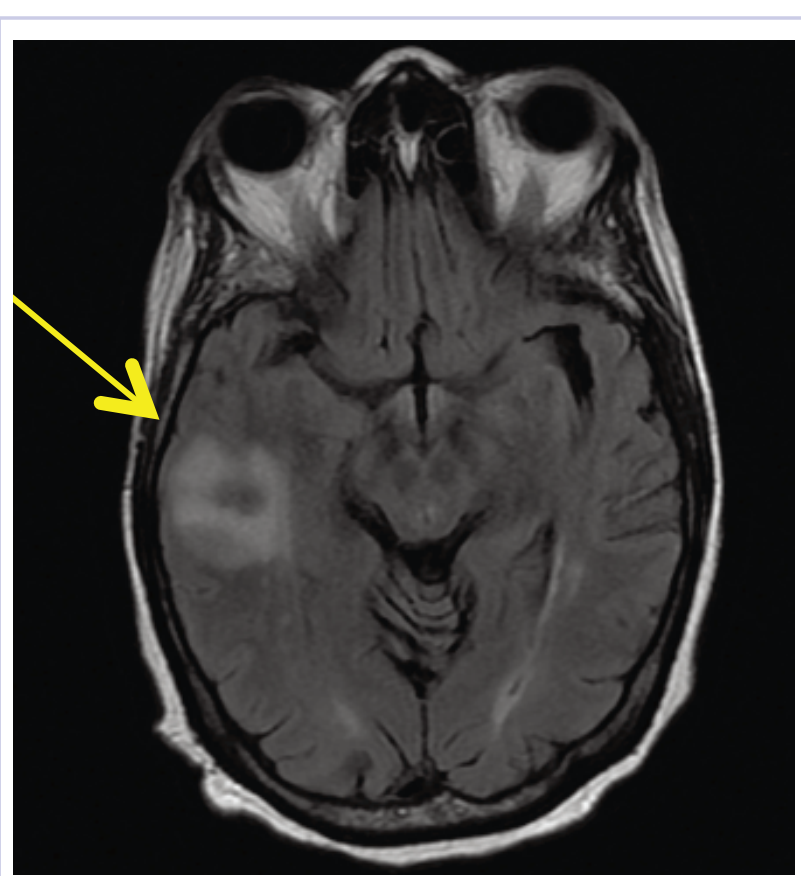

FIGURE 1 Case 1 - A magnetic resonance image of the brain showing right temporal lobe mass.

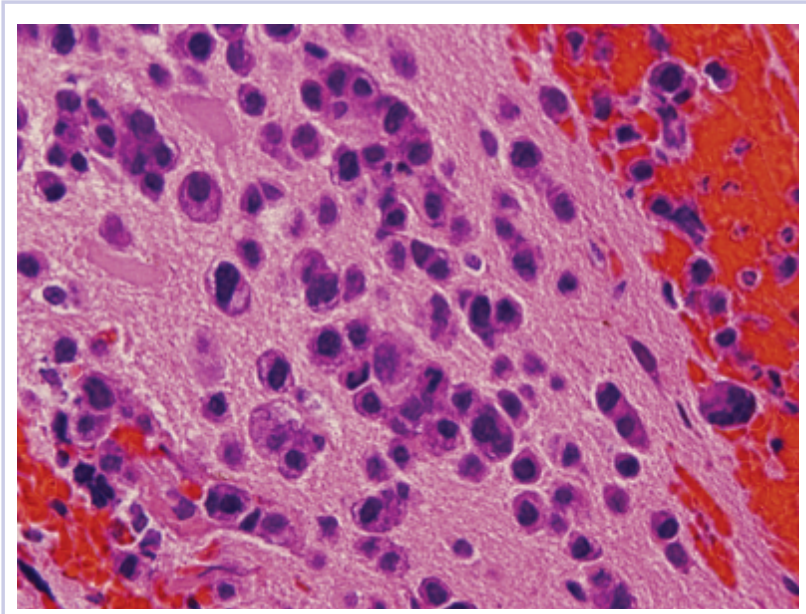

FIGURE 2 Case 1 - Histology of brain mass biopsy (H/E x400).

complaining of persistent headaches and gait abnormalities. Magnetic-resonance imaging (MRI) of the brain showed metastases in the right temporal tip, right sphenoid wing extending to the brain parenchyma in the temporal pole, in the dorsal cerebellum on the right, and also in the right temporal lobe (Figure 1). On examination, it was noted that she had left lower extremity weakness with muscle strength of $4 / 5$ (reduced strength, but muscle movement against gravity) and tongue deviation to the right. The results of a biopsy of the right temporal lobe mass were consistent with plasma cell myeloma (Figure 2). Whole brain irradiation was initiated, but discontinued after $2500 \mathrm{cGy}$ because of worsening neurocognitive function in the patient. The patient died 1 month after CNS involvement was diagnosed, which was 18 months after the initial multiple myeloma diagnosis.

\section{Case 2}

A 49-year-old African American man diagnosed with stage II IgG lambda multiple myeloma, according to the International Staging System, presented with multiple lytic lesions of the skull and a lytic lesion at the fourth cervical vertebrae $(\mathrm{C} 4)$, but with no other end-organ damage. A bone marrow biopsy revealed 75\% CD138-positive plasma cells with normal cytogenetics. FISH studies for myeloma-associated abnormalities revealed monosomy for chromosome 13. The patient received $20 \mathrm{cGy}$ of palliative radiation to the $\mathrm{C} 4$ vertebral lesion, then weekly bortezomib $1.5 \mathrm{mg} / \mathrm{m}^{2}$ and dexamethasone $20 \mathrm{mg}$ for 4 cycles with a very good partial response. He underwent ASCT about 7 months after diagnosis, which resulted in complete remission with no detectable $\mathrm{M}$ protein and normal free light chains at reassessment. Lenalidomide 5 $\mathrm{mg}$ daily for 21 of 28 days as maintenance was started but quickly discontinued after the patient developed a rash. After 7 months of observation, the patient showed a rapid rise in his $\mathrm{M}$ protein and subcutaneous masses were noted on clinical examination. Further work-up with a PET scan revealed extreme widespread multiple myeloma with extensive osseous involvement, several soft tissue masses, and lymphadenopathy. A fine-needle aspirate of a right axillary mass was consistent with plasma cell myeloma. The patient was started on DT-PACE (dexamethasone $40 \mathrm{mg}$ orally daily for 4 days; thalidomide $400 \mathrm{mg}$ PO at night; 4-day continuous infusion of cisplatin $10 \mathrm{mg} /$ $\mathrm{m}^{2}$ a day, doxorubicin $10 \mathrm{mg} / \mathrm{m}^{2}$ a day, cyclophosphamide $400 \mathrm{mg} / \mathrm{m}^{2}$ a day, and etoposide $40 \mathrm{mg} / \mathrm{m}^{2}$ ) every 21 days and completed 3 cycles with excellent metabolic response noted on the PET scan after 2 cycles and very good partial response hematologically.

The patient had a delay in the fourth cycle of therapy and presented with weakness to the lower extremity, diplopia, headaches, and chemosis (Figure 3A). His lacrimal glands were enhanced and enlarged on MRI of the brain, and the cerebrospinal fluid (CSF) was positive for myeloma cells (Figure 3B). A biopsy of the left conjunctival lesion was consistent with involvement by myeloma (Figure 3C). The patient received intrathecal methotrexate $12 \mathrm{mg}$ weekly until sterilization of the CSF was achieved. The retro-orbital lesion was treated with local radiation. He received 2 additional cycles of DT-PACE to which bortezomib $1.5 \mathrm{mg} / \mathrm{m}^{2}$ weekly and monthly intrathecal methotrexate treatment were added. His current status is partial remission of multiple myeloma. At 11 months after the diagnosis of CNS involvement, he was noted to have a partial hematologic response and good clinical 

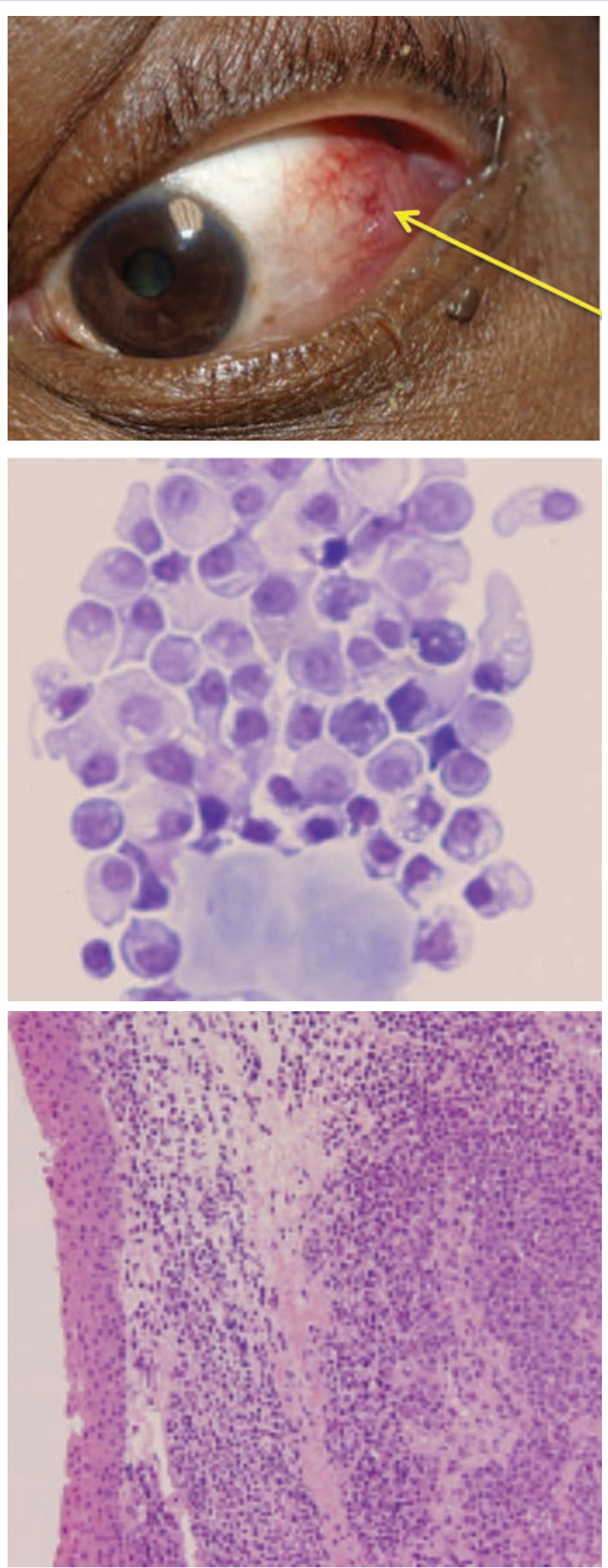

FIGURE 3 Case 2 - A, Chemosis of left eye secondary to myeloma infiltrate. B, Cerebrospinal fluid cytology showing clumps of myeloma cells (Giemsa x400). C, Biopsy of left eye conjunctiva revealing infiltration by myeloma (H/E x200). response with no evidence of CNS disease. However, the patient died at 20 months after diagnosis of CNS disease due to recurrence.

\section{Discussion}

When each of these patients presented initially, no risk factors (ie, unfavorable cytogenetics, heavy tumor burden, plasmablastic morphology, or extramedullary disease) believed to be linked with developing CNS disease were present. Both cases ultimately fell into the high-risk category for developing CNS disease after 6 months (Case 1) and 19 months (Case 2) of diagnosis due to the development of extramedullary disease. The time to developing CNS disease from initial diagnosis was around 17 months for Case 1 and around 24 months for Case 2, 10 months and 5 months, respectively, after developing highrisk disease. CNS involvement in multiple myeloma usually occurs between 8.5 and 13 months after initial diagnosis. ${ }^{6}$ Presentation with CNS disease was noted in our patients within 7 months (Case 1) and 3 months (Case 2) of ending aggressive chemotherapy. In both cases, the overall tumor burden was low at the time of diagnosis of CNS involvement. It has been previously observed that multiple myeloma can invade the central nervous system at any stage of the disease. ${ }^{7}$ The development of CNS disease with low hematologic burden suggests that the brain is a sanctuary site for aggressive myeloma because it cannot be reached by chemotherapy. Myeloma cells in these circumstances may be poorly differentiated and non-secretory and may reach the brain by infiltration of the arachnoid veins through circulation. ${ }^{8}$

In most instances, multiple myeloma is an incurable disease. However, the evolution of treatment, including ASCT and new immunomodulatory agents, has increased the overall survival. ${ }^{9,10}$ It is not uncommon for patients to achieve a complete response or very good partial response

TABLE 1 Features associated with CNS multiple myeloma
Feature
High myeloma burden
Deletion of chromosome 13/
deletion of p53 or $17 \mathrm{p} 53$
Elevated LDH
Less common immunoglobulins
Durie-Salmon stage III disease
Plasma cell leukemia
Extramedullary disease
CNS, central nervous system; LDH, lactate dehydrogenase
aDrurie-Salmon staging system is used to assess and classify multiple myeloma
based on the number of myeloma cells in the body: stage 1 , low cell mass,
600 billion cells/m²; stage 2 , intermediate, $>600-1,200$ billion cells; stage 3 ,
high cell mass, $>1,200$ billion cells.


after ASCT or tandem ASCT; but the disease will more often than not relapse. Although prognostic features are determined upon presentation, it is not clear how many of these factors affect outcome. ${ }^{2}$ Prognosis with CNS involvement has historically been considered poor with a median survival of 2 months. ${ }^{11}$ In more recent years, the prognosis may or may not have improved with novel agents. The median survival in a Canadian study was 4.8 months; however in the same study, 9 of 37 patients became longerterm survivors. ${ }^{12}$ The median survival in a Greek study was 4 months in patients treated with novel agents compared with 2 months in patients treated earlier without novel agents. ${ }^{13}$ Therefore, as far as we know, Case 2 is already one of the longest survivors.

\section{References}

1. Rajkumar SV. Clinical features, laboratory manifestations, and diagnosis of multiple myeloma. UpToDate. http://www.uptodate.com/contents/clinical-features-laboratory-manifestations-and-diagnosis-ofmultiple-myeloma. Updated January 14, 2016. Accessed September 12, 2016.

2. Rajkumar, SV. Staging and prognostic studies in multiple myeloma. UpToDate. http://www.uptodate.com/contents/staging-and-prognostic-studies-in-multiple-myeloma. Updated January 12, 2016. Accessed September 129, 2016.

3. Ulusakarya A, Youssef A, Bayle C, Vantelon JM, Munck JN. Plasma cell meningitis after an autograft in a patient with multiple myeloma. Leuk Lymphoma. 1999;34:633-634.

4. Fassas AB, Ward S, Muwalla F, et al. Myeloma of the central nervous system: strong association with unfavorable chromosomal abnormalities and other high-risk disease features. Leuk Lymphoma. 2004;45:291-300.

5. Rasche L, Bernard C, Topp MS, et al. Features of extramedullary myeloma relapse: high proliferation, minimal marrow involvement, adverse cytogenetics: a retrospective single-center study of 24 cases. Ann Hematol. 2012;91:1031-1037.

6. Gangatharan SA, Carney DA, Prince HM, et al. Emergence of central nervous system myeloma in the era of novel agents. Hematol Oncol. 2012;30:170-174.

7. Schluterman KO, Fassas AB, Van Hemert RL, Harik SI. Multiple myeloma invasion of the central nervous system. Arch Neurol.
Is CNS prophylaxis or screening indicated in patients with multiple myeloma? In large case series, $0.8 \%-1 \%$ of patients with myeloma developed CNS involvement during the course of their disease. ${ }^{8,13,14}$ There is consensus on the high-risk features associated with CNS involvement in multiple myeloma ${ }^{11-14}$ (Table). Therefore, in patients with extramedullary disease and/or with other high-risk features especially after ASCT, the threshold for cerebrospinal fluid screening should be low. However, in patients with multiple myeloma and unexpected neurologic symptoms, a brain MRI or lumbar puncture with cerebrospinal fluid studies is definitely warranted. Due to the rarity of the incidence of multiple myeloma with CNS involvement, universal screening is not indicated at this time.

\section{4;61:1423-1429}

8. Abdallah AO, Atrash S, Shahid Z, et al. Patterns of central nervous system involvement in relapsed and refractory multiple myeloma. Clin Lymphoma Myeloma Leuk. 2014;14:211-214.

9. Veinstein A, Brizard A, Randriamalala E, Babin P, Preud'homme JL, Guilhot F. Central nervous system relapses after autologous stem cell transplantation for myeloma. Report of two cases. Hematol Cell Ther. 1997;39:327-330.

10. Munker R, Shi R, B. Nair B, et al. The Shreveport myeloma experience: Risk factors, outcome and other malignancies in the age of stem cell transplantation. Acta Haematol. 2016;135:146-155.

11. Nieuwenhuizen L, Biesma DH. Central nervous system myelomatosis: review of the literature. Eur J Haematol. 2008;80:1-9.

12. Chen CI, Masih-Khan E, Jiang H, et al. Central nervous system involvement with multiple myeloma: long term survival can be achieved with radiation, intrathecal chemotherapy, and immunomodulatory agents." Br J Haematol. 2013;162:483-488.

13. Katodritou E, Terpos E, Kastritis E, et al. Lack of survival improvement with novel anti-myeloma agents for patients with multiple myeloma and central nervous system involvement: The Greek Myeloma Study Group experience. Ann Hematol. 2015;94:2033-2042.

14. Yellu MR, Engel JM, Ghose A, Onitilo AA. Overview of recent trends in diagnosis and management of leptomeningeal multiple myeloma. Hematol Oncol. 2016;34:2-8. 